\title{
REPRESENTAÇÃO POLÍTICA E RELAÇÕES SOCIAIS NO BRASIL ATUAL
}

Pedro Kirst ${ }^{1}$

\begin{abstract}
Resumo
Este artigo tem como objetivo examinar a questão da representação política no Brasil contemporâneo, buscando estabelecer nexos com as relações sociais. Partindo de um referencial teórico crítico às teorias mainstream da Ciência Política, a ideia principal é considerar a historicidade e a materialidade do país, visando identificar as limitações da democracia brasileira, em particular, e das democracias liberais, em geral. Como objeto imediato, a crise recente (a partir de 2013) que acometeu o Brasil muito revela sobre as questões referentes às estruturas jurídico-política, econômica e ideológica, que serão abordadas no texto. A forma da representação política pode ser colocada em xeque, tendo em vista que há déficits quantitativos e qualitativos preocupantes, em especial nas casas legislativas. Avaliaremos o que há - ou não - de democrático no desenho atual, as estruturas que permitem tais déficits e quais as possíveis causas da chamada crise.
\end{abstract}

Palavras-chave: democracia; representação política; Brasil; relações sociais; aparelhos de Estado.

\section{Political representation and social relations in contemporary Brazil}

\begin{abstract}
This article aims to examine the political representation issue in contemporary Brazil, seeking to establish links with social relations. Using theories that criticize the Political Science mainstream, the main idea is to consider the country's historicity and materiality, trying to identify the limitations of Brazilian democracy, in particular, and of liberal democracies, in general. As an immediate object, the recent crisis (from 2013 on) that has affected Brazil reveals much about the issues inherit to its juridical-political, economic and ideological structures, which will be discussed in this paper. The form of the political representation can be put on check, considering the existence of worrying quantitative and qualitative deficits, especially in the legislative houses. What is - or is not - democratic in the current scheme will be evaluated, along with the structures that allow such deficits and possible causes of the so-called crisis.
\end{abstract}

Keywords: democracy; political representation; Brazil; social relations; State apparatus.

\footnotetext{
1 Graduado em Relações Internacionais pela PUC-SP (2015). Mestre em Ciências Sociais pela PUCSP (2019). Pesquisador da área de Ciência Política, com ênfase nos temas de representação política, democracia e Estado. Contato: pedro.kirst@gmail.com.
} 


\section{Considerações gerais sobre o modelo democrático liberal e o caso brasileiro}

Inicialmente, faz-se necessário lançar as bases teóricas desta discussão. Longe de abarcar todo o repertório existente, nesta seção procuraremos elencar as principais características das democracias liberais, com ênfase em seu sistema representativo. Nesse intento, é de suma importância considerar os fatores sociais, econômicos e ideológicos que permeiam as estruturas do Estado burguês, incluindo a jurídico-política, que se correlaciona ao modo de produção capitalista. Ademais, deve-se levar em conta a especificidade da formação social - no caso, a brasileira -, realizando uma aproximação com o contexto atual.

Para começar tal digressão, tomaremos como base alguns estudos consagrados sobre a democracia liberal. Macpherson (1978) analisa os modelos de maior destaque, partindo de alguns pressupostos aos quais devemos atentar. Para o autor, com a consolidação da classe burguesa como dominante, no final do século XVIII e início do século XIX, surgem as democracias liberais. Uma de suas premissas é, justamente, o reconhecimento da divisão da sociedade em classes (MACPHERSON, 1978, p. 27). Apesar disso, muitos dos teóricos do mainstream não veem essa cisão como algo problemático, invocando as proposições clássicas do utilitarismo, do individualismo e da meritocracia², desconsiderando aspectos históricos e materiais que levaram à constituição das classes no capitalismo, como a acumulação primitiva e a exploração implícita na esfera produtiva, discutidas principalmente por Marx (2011, cap. 5; cap. 24). A visão dominante repousa sobre o equívoco de desconsiderar tais questões, que são de suma importância para compreender os fenômenos para além da esfera das aparências, à medida que conferem concretude às análises.

Os modelos democráticos liberais aparecem tanto nas formas mais simplificadas - como a democracia protetiva de Bentham -, quanto nas mais elaboradas - como a desenvolvimentista de J. S. Mill - sem nunca abandonar alguns preceitos básicos. Do ponto de vista jurídico, todos os indivíduos, sejam trabalhadores ou proprietários, são colocados como "iguais" pelo direito burguês (ver NAVES, 2000, p. 65), permitindo, principalmente, a exploração econômica mediante a possibilidade de "livre" assinatura dos

\footnotetext{
${ }^{2}$ Referem-se, principalmente, à conceituação de Mill (sd.) sobre a soma das felicidades individuais, que resultaria em um maior bem-estar geral em determinada sociedade. Por "felicidades individuais", pode-se entender o acúmulo de riquezas, a ser realizado de maneira autônoma e baseado no mérito.
} 
contratos de trabalho. No aspecto superficial - da circulação das mercadorias -, aparenta ser uma troca justa: paga-se um salário correspondente ao necessário à subsistência do trabalhador. Porém, no aspecto mais profundo - das relações de produção -, existe a exploração do sobretrabalho (mais-valia), processo pelo qual o proprietário amealha uma quantidade superior à paga ao trabalhador, mesmo considerando os custos da produção. Esse excedente provém do trabalho não remunerado do empregado, o que é possível no modo de produção capitalista.

Isso se correlaciona ao modelo político ${ }^{3}$. No século XX, torna-se mais clara a penetração dos princípios mercadológicos na teorização democrática liberal. A "circulação das vontades políticas", trazida por Schumpeter (1961) em muito se assemelha à circulação das mercadorias - ou ao aspecto ilusório - na esfera econômica. Para o autor, o regime político existente - e, portanto, o único possível ${ }^{4}$-, seria comparável ao mercado, regido pelas normas da livre-concorrência. Todos seriam livres para disputar os cargos políticos - em consonância com o princípio da igualdade jurídica-, sendo que os mais capazes seriam eleitos.

Entretanto, as "vontades políticas" podem ser manufaturadas, tendo em vista a suposta irracionalidade dos eleitores e a ação de lobistas, políticos e propagandistas, mantendo o poder reservado às "elites". As eleições, portanto, seriam meros rearranjos institucionais para decidir qual das elites deteria o poder político naquele momento, podendo ser regularmente substituída por outra por meio das eleições.

Macpherson (1978, p. 90) atenta ao fato de que, dessa forma, as demandas, para serem efetivas, dependeriam essencialmente do dinheiro. Esse recurso seria utilizado, por exemplo, tanto na realização de peças publicitárias quanto no financiamento das campanhas políticas, tema tão recorrente no cenário político brasileiro atual.

Durante o século $X X$, o modelo schumpeteriano foi referendado como "vencedor" por teóricos proeminentes como Huntington (1994), que reafirmou que as definições "racionalistas, utópicas e idealistas", em uma alusão ao socialismo, foram substituídas pelas "empíricas, descritivas, institucionais e processuais" (HUNTINGTON,

\footnotetext{
${ }^{3}$ Aqui, é importante destacar que não se trata de uma relação de causa e efeito, partindo do econômico para o político. A crítica ao economicismo deve ser feita, no sentido de que são as relações sociais que moldam os modelos político e econômico, e não o contrário. Além disso, devese considerar a indissociabilidade entre essas duas esferas, evitando, assim, uma análise simplificada. 4 Nota-se que o objetivo de Schumpeter era o de descrever o modelo político, sem emitir, teoricamente, nenhum juízo de valor.
} 
1994, p. 16), sendo que, para existir uma democracia liberal, bastariam as eleições livres e regulares, com 0 Legislativo operante. Tal simplificação seria ideal, pois poderia ser facilmente assimilada pela população.

É importante notar que essa teorização, aliada aos princípios do neoliberalismo, ganhou força com o relativo insucesso da União Soviética, especialmente a partir dos anos 1980. Muitos ditos socialistas abandonaram diversos pressupostos fundamentais, em nome de uma "gestão humanitária" do capitalismo5.

Não por acaso, o processo de "reabertura democrática" no Brasil, posterior à ditadura militar (1964-1985), foi atingido em cheio por essas teorias, tendo Huntington participado nesse momento, após a elaboração do Relatório Trilateral (CROZIER; HUNTINGTON; WATANUKI, 1975). No final da ditadura, foram crescentes as demandas de movimentos sociais e sindicatos, ao mesmo tempo em que se desenrolava uma crise econômica e ocorriam mudanças no interior do bloco no poder, com a ascensão da burguesia financeira, em detrimento da industrial, privilegiada nas décadas anteriores.

Crozier (idem) havia notado uma "exacerbação das tensões", a nível global, com o advento da maior representação política de diversos grupos no pós-guerra. De maneira similar, havia pressão popular no Brasil dos anos 1980. Isso se encaminhava para um estágio de "ingovernabilidade", na perspectiva dos conservadores, tendo em vista 0 aumento significativo de demandas. A solução seria o Estado mínimo, gestada pelos neoliberais desde os anos 1940. Todavia, tal modelo de Estado, de acordo com Moraes (1996), é inexistente. Nos momentos de crise, podem ser aplicadas duas soluções, ambas intervencionistas, consonantes ao modo de produção capitalista: o modelo keynesiano, baseado na restauração da demanda, ou o neoliberal, voltado à recuperação econômica por meio de medidas de austeridade e pagamento de dívidas. "Em qualquer das hipóteses, não se tem o Estado mínimo que a propaganda neoliberal de tanto se vale para impingir uma virulenta política antissocial, considerada tão vital para a recuperação da economia capitalista" (idem, p. 7).

Durante 0 processo que gerou a atual democracia limitada brasileira (a partir de 1985), pôde-se notar uma direção burguesa mesmo nas campanhas contra a ditadura, como as "Diretas Já!". 
De acordo com Nery (2014), tal ingerência teve efeitos negativos para as camadas populares, permitindo, por exemplo, a manutenção dos militares na cena política. Houve também uma canalização das pressões populares para o meio institucional (MACIEL, 2014, p. 275), que não possui e segue sem possuir um caráter efetivamente democrático, pois não atende satisfatoriamente às demandas dessa camada da sociedade. Conforme veremos no decorrer deste artigo, as instituições compreendidas aqui como aparelhos de Estado - não são neutras, diferente do que é convencionalmente difundido. Dentro do referencial teórico aqui utilizado, esses aparelhos fazem parte da estrutura jurídico-política do Estado burguês, sendo funcionais à sua manutenção. Portanto, a canalização das demandas populares para o meio institucional termina, por consequência, arrefecendo a capacidade de desenvolvimento das lutas.

Além disso, estabeleceu-se um regime político que ficou conhecido como "presidencialismo de coalizão", nas palavras de Abranches (1988). Focado essencialmente nas relações existentes entre o Legislativo e o Executivo, a partir de uma engenharia institucional repleta de dispositivos - por muitas vezes, falhos - tal modelo esconde seu caráter fortemente ideológico. De acordo com Martuscelli (2010, p. 60), a visão processual contida no presidencialismo de coalizão escamoteia aspectos de nossa realidade social, ignora as questões de classe, os processos históricos e a materialidade da formação social brasileira. Não sendo sequer mencionados tais aspectos, a aparência é a de que a política no Brasil se resume às tensões entre esses dois poderes.

A herança colonial, a inserção dependente da economia no capitalismo global, os resquícios da ditadura: nada disso é considerado no debate político - especialmente no plano institucional - brasileiro $^{6}$. A noção de participação política - ou seja, os meios pelos quais o povo pode e deve atuar politicamente - está restrita, no imaginário da maior parte da população, às eleições, minimizando outras formas de agir, como a construção de movimentos sociais, de associações de trabalhadores, etc. As representações de classe, raça, gênero, etc. encontram-se deficitárias tanto do ponto de vista descritivo - da

\footnotetext{
${ }^{6}$ Esses três aspectos, longe de esgotar todos os exemplos possíveis, estão relacionados às questões de raça, classe, gênero, etc., dentro do contexto da historicidade e materialidade da formação social brasileira. O Brasil colônia, por exemplo, nos deixou como herança não só o racismo estrutural - entendido como preconceito racial, somado às condições socioeconômicas legadas à população negra -, mas também a inserção econômica dependente do país no cenário internacional, enquanto exportador de produtos de baixo valor agregado e importador de industrializados de alto valor e de maquinário. Esses aspectos serão retomados mais adiante, estabelecendo os vínculos com as questões democrática e representativa.
} 
quantidade de representantes -, quanto da perspectiva de efetivação das demandas históricas e urgentes destes grupos, como garantia de leis trabalhistas, cotas, salários iguais, entre outras.

O Congresso eleito em 2014 (mandato 2015-2019), por exemplo, registrou números baixíssimos de representatividade dos grupos sociais citados. Mulheres eram apenas 10\% dessa legislatura (IPU, 2015); negros e pardos somavam 24\% (SARDINHA, 2014). Na contramão, os autodenominados "empresários" estavam sobrerrepresentados, com 190 deputados (CARAM; SOUZA, 2014) mais de um terço da Câmara -, enquanto os representantes oriundos de movimentos sociais perderam cadeiras, oscilando de 86 para 43 (idem), em relação ao Congresso anterior.

De acordo com Almeida (2014, p. 6), houve "um extraordinário recuo das classes populares na cena política", levando a "um dos Congressos mais conservadores dos últimos cinquenta anos, com aumento do número de partidos nanicos de direita e de eleitos bancados pelos grandes capitalistas" (idem, ibidem). Tal observação encontra respaldo na teorização poulantzana, pela qual notamos que "as relações políticas e as relações ideológicas se materializam e se encarnam, como práticas materiais, nos aparelhos de Estado" (POULANTZAS, 1975, p. 26, itálicos no original). Ou seja, o quadro observável em determinado aparelho decorre das relações sociais, não podendo a análise estar alheia a elas.

Lançadas essas bases, e sem pretensão de esgotar o tema, veremos alguns aspectos notáveis da representação política em geral e das especificidades da formação social brasileira, para podermos avançar para uma análise da (crise da) representação no Brasil, procurando identificar os interesses existentes, que privilegiam a classe dominante em detrimento dos trabalhadores, negros e mulheres, especialmente os mais pobres. As relações entre os poderes que, vistas de maneira isolada às relações sociais, detêm o caráter ideologizante destacado por Martuscelli (op. cit.), devem ser esmiuçadas, com o intuito de entender quais os reais interesses de classe por trás da alegada crise.

\section{A representação política nas democracias liberais $e$ as especificidades do Brasil}

Esboçamos ideias relativas à forma burguesa dos modelos democráticos. Podemos ver, agora, com mais vagar, mesmo que em linhas gerais, alguns pontos existentes no debate da 
representação política, junto a críticas necessárias ao arrazoado liberal.

Alguns conceitos abordados por Pitkin (1972) são bastante presentes nas formulações liberais atuais acerca do tema. Do ponto de vista formalístico, espera-se "autorização" - antes do início do mandato, por meio do voto - e "responsabilização" depois, por meio da reeleição, ou não. Entretanto, a própria autora se refere ao conteúdo dos mandatos como uma "caixapreta" ("b/ackbox") (PITKIN, 1972, pp. 39; 58; 238), momento sobre o qual há pouco controle dos eleitores sobre as ações dos representantes. Cánepa (2005) demonstra que tanto a autorização quanto a responsabilização encontram-se "fora" da atividade representativa, referindo-se somente à forma como esta se dá (idem, pp. 51-2), sendo, portanto, insuficientes para verificar o conteúdo da representação, ou seja, a prática política dos representantes.

Dentre outros desenvolvimentos apontados por autores do mainstream para contornar eventuais distorções na representação nesses modelos - quando o eleito não cumpre a plataforma, ou quando os eleitores não têm acesso à totalidade das informações -, são propostas a prestação de contas, a existência de sistema de recompensas e a presença de órgãos observadores, entre outros, embora reconheçam que a democracia" "não possa assegurar a representação", sendo que "o controle dos cidadãos sobre os políticos é, no melhor dos casos, altamente imperfeito na maioria das democracias" (ver MANIN; PRZEWORSKI; STOKES, 2006, p. 132).

Além disso, o conceito de "no lugar de" ("standing for") também trazido por Pitkin (op. cit.), apresenta outro problema na visão de Cánepa. Tal ideia trata da representação como uma substituição descritiva da sociedade pelo parlamento, criando uma espécie de microcosmo (CÁNEPA, op. cit., p. 52). Ignorando as distorções já apresentadas, relacionadas especialmente ao financiamento das demandas efetivas, a partir disso seria desejável que as instâncias representativas legitimadas por sufrágio fossem compostas, descritivamente, de modo diretamente proporcional ao estrato social correspondente. Exemplificando, por essa ótica, a proporção de mulheres no Congresso Nacional deveria ser paritária, ou até levemente superior à de homens, pois, de acordo com o IBGE (2010), a sociedade brasileira é composta de $51 \%$ de

7 E aqui, destaca-se: democracia liberal, pois é essa que os autores reconhecem como "democracia".

CSOnline - Revista Eletrônica de Ciências Sociais, Juiz de Fora, n. 30 (2019) 
mulheres. Entretanto, os números das eleições mais recentes (2018) mostram que apenas $15 \%$ dos congressistas são mulheres, apesar de ser esta a maior proporção já registrada no Brasil. O mesmo vale para negros, pardos, trabalhadores, etc., em diferentes proporções. Por outro lado, encontram-se sobrerrepresentados homens, brancos e empresários, que não são a maioria da população brasileira.

Apenas esse fato já demonstra um déficit representativo bastante relevante. Porém, ater-se somente à representação numérica chamada descritiva - tampouco ajuda a compreender, na prática, a ausência de representação das pautas históricas - no conteúdo dos mandatos - de determinados grupos sociais majoritários, enquanto parte da população - embora vistos como minorias do ponto de vista social. Um deputado negro, por exemplo, pode ter uma posição contrária às políticas de reparação voltadas à população negra. Da mesma forma, um deputado homem pode ser a favor das bandeiras históricas dos movimentos feministas, contribuindo para o avanço de matérias nas casas legislativas, embora essa tarefa preferencialmente deva ser encabeçada pelos movimentos e atores diretamente correspondentes. Se fosse o caso, far-se-ia necessário avaliar individualmente a posição de cada um dos representantes, a fim de detectar quem eles de fato representam.

Esse nível de preciosismo terminaria por extrapolar o escopo deste trabalho, além de perder a perspectiva geral. É importante ressaltar, entretanto, que há indícios de que a própria organização do aparelho de Estado em questão - o Congresso - contribui para a manutenção do status quo. Coelho e Santana (2010), em uma análise sobre o comportamento da geração de 1968 - que participou da resistência contra a ditadura militar - no Congresso Nacional (2003-2007), concluem que "as regras que regem a organização política do Congresso impedem de forma evidente que manifestações mais radicais se convertam em projetos de lei viáveis" (idem, p. 304), explicando a tendência recente mais conservadora desses representantes, outrora mais radicalizados, quando inseridos no aparelho de Estado.

Por outro caminho, porém com conclusão semelhante, Saes (1987) traz elementos que nos ajudam a compreender o caráter geral dos aparelhos de Estado, entre eles, o parlamento. Pelo fato de estar inserido na estrutura jurídico-política do Estado burguês, "o [p]arlamento [...], em qualquer caso, ele é burguês, pelo seu funcionamento" (idem, p. 54). Ou seja: são as práticas existentes 
no interior desse aparelho que fazem com que ele seja funcional à classe dominante. Isso contradiz a ideia de que os aparelhos são neutros. Eles pressupõem as classes e, embora sejam arenas passíveis de disputa, em última instância jamais serão funcionais aos interesses da classe dominada. Seria impossível que os dominados tivessem a totalidade de suas demandas supridas sem a substituição dos aparelhos burgueses por outros, funcionais a seus desígnios. Sem dúvida, tal mudança faria parte de ainda maiores alterações nas relações sociais, inclusive nas relações de produção.

Ainda assim, é possivel analisar as sub-representações e as sobrerrepresentações do ponto de vista descritivo (quantitativo) no Brasil atual, pois podemos perceber como as relações sociais afetam os aparelhos de Estado. Conforme Poulantzas (1975, p. 30), "[...] é a luta de classes, em todos os níveis, que dá comando aos aparelhos". No clássico debate com Miliband, o autor também afirma que "a participação direta dos membros da classe dominante no aparelho do Estado não é causa e sim o efeito" (POULANTZAS, 1982, p. 226) das relações objetivas entre a classe burguesa e o Estado.

Somando essas duas variáveis, temos que a sobrerrepresentação da classe dominante, em termos de quantidade, em um determinado aparelho de Estado não é o que provoca a dominação de classe, mas pode demonstrar, por outro lado, um efeito das disparidades existentes na sociedade. Trocando em miúdos, não é a quantidade de representantes da burguesia no Congresso Nacional que provoca retrocessos nas pautas trabalhistas, mas as relações sociais existentes que fazem com que seja possível um número exacerbado desses representantes no parlamento.

A fim de evitar mal-entendidos, cabe destacar que não é possível estabelecer, de maneira direta, uma relação simples de causa e efeito. O próprio Poulantzas se previne quanto a isso, quando afirma, ainda durante o debate com Miliband, a existência da autonomia relativa do Estado, que age como fator de coesão da classe dominante - e de fragmentação da classe dominada. Ou seja, mesmo com uma maioria de representantes da classe dominada em determinado aparelho, seria possível que seu funcionamento continuasse a atender à classe dominante, conforme destacamos anteriormente, pois esse aparelho faz parte da estrutura jurídico-política do Estado burguês. Os aparelhos são burgueses e, embora admitam concorrência - do ponto de vista 
do liberalismo que permeia a maioria dos modelos democráticos atuais -, nunca serão o caminho de seu próprio fim. Apesar disso, há motivos para haver uma disputa crítica pelos aparelhos, em especial desde uma perspectiva tática, objetivando a sua subsequente transformação.

Feita essa ressalva, podemos chegar a uma conclusão que serve à análise conjuntural que pretendemos fazer. Embora não seja possível estabelecer os nexos de causa e efeito de modo direto, se analisarmos do ponto de vista das relações sociais, percebemos que a questão representativa no Brasil contemporâneo é quase uma caricatura. Representantes que defendem abertamente os interesses da burguesia e do patriarcado; que advogam pela abolição das leis trabalhistas e das políticas afirmativas; que são contra a promoção da cultura e a preservação do meio ambiente; e assim por diante. Todos esses temas amplificaram-se no debate político dos últimos anos, sem que se considere a materialidade e a historicidade de nossa formação social, graças ao acirramento das tensões sociais no Brasil.

O que ocorreu, especialmente a partir de 2013, para que houvesse tamanho avanço das forças conservadoras e antipopulares? É evidente que não existe resposta pronta para tal questionamento e que, muitas vezes, a análise no "calor do momento" pode provar-se errônea, ou parcialmente equivocada, em médio e longo prazos. Entretanto, a perspectiva histórica e materialista pode ajudar a perceber a concretude de determinados fenômenos, quando se trata deste tipo de análise conjuntural.

Primeiramente, devemos recordar alguns aspectos cruciais da formação social brasileira. É difícil realizar qualquer tipo de análise política do Brasil sem considerar, por exemplo, o passado colonial, o consequente processo de industrialização, os processos ditatoriais, etc. Da mesma forma, não se pode ignorar quais foram as práticas correntes no interior da sociedade durante a época da escravidão, qual foi o papel das mulheres, não somente na política, até meados dos anos 1950, quais mudanças ocorreram nos anos 2000, com o aumento do consumo e renda das famílias, mas com a ausência de politização̊ ${ }^{8}$. Poderiam ser detalhadas

${ }^{8}$ De acordo com ALMEIDA (2018, p. 195): "quem estava na faixa dos dez anos em 2003 [...] chegou a 2013 sem passar por qualquer grande contato com a política, a não ser no plano institucional [...], tendendo a manter em relação a ela [...] uma atitude de desprezo". A partir disso, podemos inferir que a preocupação fundamental dos governos à época não foi a de garantir maior autonomia política à população, mas de trazer a chamada "inclusão social" por meio do aumento de renda e consumo, sem que houvesse um espaço maior para reflexão e ação política, que efetivamente 
inúmeras especificidades da formação social brasileira, o que certamente não caberia neste artigo. Para simplificar, levantaremos alguns pontos, sem ânimo de fechar questões, apenas com o intuito de direcionar o debate.

No que se refere ao estabelecimento do modo de produção capitalista no Brasil, fator de suma importância para os desdobramentos políticos, devemos atentar a alguns pontos. Recorrendo a Sérgio Silva (1986), temos a noção de que a burguesia industrial conservou fortes laços com a burguesia comercial, que acumulou seu capital a partir da exploração colonial anterior, separando-se da fração fundiária, passando a exercer as funções bancária e exportadora. A fração industrial, portanto, dependia da importação de maquinário e do capital da burguesia comercial, tornando-se subalterna tanto internamente, quanto internacionalmente, em posição de dependência em relação aos países capitalistas centrais. Além disso, nos momentos em que teve a possibilidade de dinamizar as forças produtivas, como nos anos 1930, com a crise de hegemonia, a burguesia industrial demonstrou-se acovardada, sendo o "vácuo" no poder ocupado pela burocracia de Estado, com Vargas.

Tais eventos trouxeram consequência políticas, especialmente para a classe trabalhadora, em grande parte proveniente do campo, onde prevaleciam as relações paternalistas (mesmo entre o campesinato livre). Conformada também por imigrantes, exescravos e seus filhos, não houve uma unidade sindical muito coesa nos centros urbanos, sendo que, do ponto de vista institucional, os partidos que surgiram tiveram origem na própria burocracia de Estado. Anteriormente, na época da política do "café com leite", a baixa dinamização política dos trabalhadores refletia na (ausência de) organização da classe dominante, que pouco se preocupava com os meios institucionais, mantendo sua dominação pela via extrapartidária.

Se a participação político-partidária já não poderia mais ser expressamente negada, como vimos na seção inicial, pois todos os indivíduos em uma sociedade burguesa são juridicamente iguais, outros percalços eram colocados. No princípio, houve o voto censitário, que não fere os princípios liberais, muito pelo contrário: pressupõe que basta 0 indivíduo se esforçar para acumular suficiente riqueza. De modo similar, impediu-se até 1985 , 
- voto dos analfabetos. Ora, bastaria estudar para obter a permissão. Tais medidas atingiam em cheio os trabalhadores, com agravantes sórdidos, especialmente para a população negra. As mulheres, até a Constituição de 1934, via de regra, estavam afastadas da política, enquadradas nas restrições censitárias ou escolares, sendo consideradas dependentes de seus pais, maridos, ou mesmo irmãos e filhos, em virtude da estrutura patriarcal.

Entre 1945 e 1964, houve um crescimento industrial e alguns avanços políticos, estes suplantados pela ditadura militar. É interessante notar como se conformou o bloco no poder ${ }^{9}$ durante o período ditatorial, constituindo o que foi chamado, por alguns autores, de "tripé". Composto pelo capital privado nacional e pelas empresas estatais - com maior participação total - e pelo capital privado internacional, esse tripé favoreceu o capital nacional, público e privado. Faz-se desnecessário comentar o caráter antidemocrático do período que durou até 1985, no curto espaço deste artigo. Todavia, é interessante destacar a mudança no bloco no poder, onde se organizam as frações burguesas, no final desse período. A crise que atingiu o Brasil na década de 1980 provocou uma mudança na orientação da política econômica estatal, com a crescente neoliberal (SAES, 2001, p. 129). A hegemonia no bloco no poder passou a ser do capital financeiro, no período final da ditadura, tendo efeitos notáveis tanto no momento do estabelecimento da democracia limitada quanto nos dias atuais. Ocorreu uma reacomodação dentro do subsistema, sem que houvesse uma efetiva ruptura, embora as tensões entre as frações burguesas continuem a existir. De Sarney a Bolsonaro, a fração financeira é a que deteve poder para influenciar os rumos econômicos e políticos do Brasil.

\section{A crise recente da Nova República}

Feito esse apanhado geral, podemos nos debruçar, agora, sobre os episódios mais recentes da Nova República. Após os governos Fernando Collor de Mello, Itamar Franco e Fernando Henrique Cardoso, todos de inspiração fortemente liberal, elegeram-se, por quatro vezes seguidas, os candidatos petistas, primeiro com Luiz Inácio Lula da Silva e, depois, com Dilma Rousseff. Embora contrastantes em diversos aspectos em relação aos anteriores - e até mesmo entre si - os governos do Partido dos Trabalhadores

\footnotetext{
9 "Trata-se daquilo que chamarei de conceitos de estratégia [...]. é [...] o caso [...] do conceito de 'bloco no poder', designando uma aliança específica das classes e frações de classe dominantes [...]" (POULANTZAS, 1975, pp. 25-6, itálico no original).
} 
(PT) não eliminaram, de modo algum, a hegemonia da fração financeira no bloco no poder. Houve uma acomodação favorável à fração interna - industriais e agronegocistas em sua maioria, de caráter "exterocentrado" (ALMEIDA, 2015, p. 151) -, sem que isso motivasse uma quebra da prevalência do capital financeiro.

Entretanto, a chamada "crise", que se inicia em 2013, evolui em 2014 - mesmo com a reeleição de Dilma - e se agrava ainda mais em 2015, culminando com o processo de impeachment em 2016, teve como principal consequência política a mudança total de plataforma governamental. Embora Temer e Dilma formassem uma chapa em 2014, antes mesmo da destituição da presidenta já circulava abertamente o documento "Ponte para o Futuro", assinado pelo PMDB, contradizendo muitas das propostas da plataforma eleita.

Para entendermos esse processo, é importante notar que o conceito de "crise", no modo de produção capitalista, nem sempre contém a noção de "destruição", mas, sim, de "reprodução". Conforme Poulantzas (1977 apud MARTUSCELLI, 2016, p. 14), a crise é uma "situação particular de condensação de contradições" que, em um sentido reprodutivo, pode "condicionar a ocorrência de mudanças no bloco no poder ou nas alianças de classes formadas na cena política, podendo vir a promover alterações, respectivamente, nas formas de Estado, de regime ou de governo" (idem, p. 16), sem que haja uma mudança estrutural no funcionamento capitalista. Ou seja: as crises podem ser funcionais e necessárias à manutenção do modo de produção capitalista, não significando sua derrota, principalmente quando não são acompanhadas de importantes mudanças sociais.

Além das dificuldades econômicas, em parte decorrentes da crise global de 2008, os entraves políticos começaram a se manifestar ${ }^{10}$. Sob o pretexto da "ingovernabilidade", em grande parte fabricada pelo Congresso Nacional, estabeleceu-se que a solução seria a derrubada de Dilma. Isso demonstra, na prática, como o presidencialismo de coalizão funciona de maneira ideologizante, limitando a política às relações entre os poderes, ocultando as relações de classe, conforme vimos anteriormente. Por exemplo: a ascensão da "classe C" durante os governos petistas incomodou muito à classe média tradicional, temerosa de sua "proletarização". Simultaneamente, à burguesia interessa a

\footnotetext{
10 Recordando que as esferas econômica e política não podem ser encaradas de maneira isolada, sendo necessário o estabelecimento dos nexos entre elas.
} 
redução do custo da mão de obra, o que veio a ser aplicado com a reforma trabalhista, o reajuste do salário mínimo sem aumento real, a aprovação da reforma da previdência, entre outras medidas. Da ótica internacional, o protagonismo do Brasil junto à América do Sul - área de grande importância para os Estados Unidos da América - e a países da África e Ásia também ameaçava mexer na balança de poder, sendo da mesma forma modificada após o impeachment.

Isso é extremamente significativo quando queremos analisar a democracia e a representação no Brasil. Se procurarmos revelar o conteúdo de classe, de raça, de gênero, entre outros, da representação política, temos, na grande maioria dos casos, medidas antipopulares, racistas e mantenedoras do patriarcado, seja nos meios institucionais ou fora deles. À parte da ausência numérica dos grupos considerados minorias sociais nos aparelhos de Estado, estão ausentes também as políticas que poderiam incentivar seu acesso. Além disso, os avanços, mesmo que tímidos, tendem a ser rechaçados pelos próprios aparelhos, sejam eles econômicos, políticos ou ideológicos.

O acesso de alunos de escolas públicas às universidades, em especial às federais, possibilitado, dentro de conhecidas limitações, nos governos petistas causou - e ainda causa - forte comoção das classes médias e daqueles que presumem ser a elite intelectual do país, que tiveram suas reivindicações recentemente respaldadas pelos dois últimos Ministros da Educação ${ }^{11}$. A PEC das domésticas, que regulamentou o trabalho realizado por uma população majoritariamente feminina, negra e pobre, foi duramente criticada pelos mesmos setores que desfilaram junto aos industriais da FIESP, clamando pela destituição de Dilma.

No Congresso Nacional, o já mencionado perfil dos seus integrantes, de maneira geral, corresponde ao direcionamento dado às matérias que são votadas - embora, como já vimos, essa correlação possa ou não acontecer. No quadriênio 2015-2019, observaram-se, claramente, dois movimentos distintos das casas representativas, que apontavam para uma mesma direção: primeiro, dificultaram ao máximo as ações da então presidenta, por meio das "pautas-bomba"; em seguida, o mesmíssimo Congresso aderiu à maioria das propostas de Temer, inclusive

11 Vélez Rodríguez afirmou que "as universidades devem ficar reservadas para uma elite intelectual" (CARTA EDUCAÇÃO, 28 jan. 2019), quando ocupava o cargo de Ministro da Educação. Seu sucessor Abraham Weintraub, entre inúmeras polêmicas, prometeu cortar as verbas de universidades que promovessem "balbúrdia" (VEJA, 30 abr. 2019). 
votando pela não instauração de investigação contra ele, mesmo diante de indícios de corrupção e de sua baixíssima popularidade.

São inúmeros os exemplos que podem ser citados na legislatura acima mencionada, cuja maioria revela o aspecto burguês das práticas do parlamento. E, como vimos, são as relações sociais que dão comando a esses aparelhos. Isso significa que, no interior da sociedade brasileira, ainda prevalecem as marcas do classismo, do racismo e do machismo, todos esses estruturais em nossa sociedade.

Os reflexos mais evidentes disso puderam ser notados nas eleições de 2018. A dita "polarização", vendida como simetricamente extremista pelos grandes meios de comunicação - mesmo se tratando de uma disputa entre a esquerda moderada e uma direita fundamentalista que flerta com o fascismo -, revelou 0 estrago feito, em parte, pela falta de politização e pelo distanciamento das bases populares, reconhecidos até mesmo por setores do PT ${ }^{12}$. Almeida (2018), apoiando-se em Oliveira (2003), aponta que os dirigentes do partido passaram a ocupar altos cargos nos fundos de pensão e no interior do aparelho de Estado, levando a "bloqueios muito objetivos a qualquer apetite para enfrentar o capital, o que se expressava em mudanças nas práticas e padrões de organização do partido, com séria redução de seu potencial de mobilização de massas" (ALMEIDA, 2018, p. 190). Outros autores também destacam a redução de candidatos provenientes da classe trabalhadora lançados pelo partido em questão, registrando diminuição de 18,9\%, em 1998, para $6 \%$, em 2014 (BOLOGNESI; COSTA; CODATO, 2016, p. 12), o que reforça essa tese ${ }^{13}$.

Essa falta de uma base social politizada contribuiu para a ascensão política de grupos que pregam a destruição da maioria das conquistas sociais, sob o verniz da "nova política", advogando pelo pretenso Estado mínimo que, corroborando as ideias de Moraes (1996), é um Estado intervencionista antipovo, com a intenção de beneficiar o lucro privado, especialmente do setor financeiro.

Setor esse que tem ganhado em muitas frentes: a reforma trabalhista - ainda com Temer - auxiliou na diminuição dos custos com a mão de obra, precarizando ainda mais o trabalhador,

12 Crítica realizada, mesmo que tardiamente, no auge da disputa eleitoral de 2018.

${ }^{13}$ Longe de atribuir a "culpa" exclusivamente a determinados atores, isso exemplifica uma das facetas que ajudam a compreender a situação, não sendo o único fator passível de análise. 
provocando $\mathrm{O}$ desuso da $\mathrm{CLT}^{14}$; 0 ritmo acelerado do desabastecimento financeiro das universidades abriu as portas para os grupos privados de ensino, com destaque para o ensino a distância; a aprovação da reforma da previdência amenizará dívidas na casa dos bilhões para grandes bancos (REDE BRASIL ATUAL, 06 jul. 2017). Todas essas medidas foram avalizadas pelos congressistas. A entrega dos recursos naturais, em especial do petróleo, na esteira da Lava Jato, ao capital estrangeiro já vem sendo feita a toque de caixa desde 2015 por meio de projetos de lei na Câmara Federal e no Senado.

No plano internacional, a autonomia dos blocos existentes na América do Sul - em especial do Mercosul, no qual o Brasil exercia protagonismo - vem sendo enfraquecida ou tem tido suas diretrizes mudadas para atender aos interesses dos Estados Unidos, em termos geopolíticos e econômicos, e, mais recentemente, da União Europeia, com o tratado de livre-comércio que vem sendo estudado, com grandes chances de enfraquecer as indústrias sulamericanas, mantendo o caráter agroexportador e dependente dessas economias.

\section{Conclusão}

Com este artigo, esperamos ter feito um apanhado, em linhas gerais, sobre a questão representativa no Brasil no momento atual. Partindo dos pressupostos comuns às democracias liberais, traçamos um recorrido para delinear a democracia brasileira, em especial a partir dos anos 1980, com o final da ditadura. Além das limitações gerais existentes em qualquer modelo democrático em sociedades capitalistas, procuramos trazer um pouco das especificidades brasileiras que, por seu caráter dependente, seu passado colonial e sua estrutura racista e patriarcal, entre outros, contribuem para um cenário ainda mais difícil em relação ao atendimento dos interesses da classe dominada e dos grupos oprimidos.

Paralelamente, procuramos demonstrar como isso se concatena com as relações sociais, no sentido em que as lutas sociais interferem nos aparelhos de Estado, sendo necessárias mudanças nessas relações para uma consequente modificação das

\footnotetext{
14 Atualmente, fala-se em uma "minirreforma", que teria como um de seus objetivos inserir, paralelamente à CLT, outra carteira de trabalho ("verde e amarela"), na qual valeria o acordo entre funcionário e patrão, fundamentado na igualdade jurídica entre ambos. As consequências, evidentemente, seriam desfavoráveis aos trabalhadores, que possuem menor margem de negociação.
} 
estruturas. Essas mudanças, por sua vez, exigem um processo dialético amplo, que carece de uma politização maior da sociedade, passando por um rompimento com a ideologia dominante, com o intuito de revelar as contradições inerentes ao modelo vigente.

A crise atual transparece muitas dessas questões, embora não indique um caminho claro a seguir. Isso se dá principalmente em função do caráter reprodutivo dessa crise, que não emergiu a partir de uma mudança qualitativa no entendimento da participação política da população em geral - no âmbito extra institucional -, mas, sim, a partir das diretrizes apontadas pela burguesia, em especial pelas frações interna e financeira, utilizando-se de todo o aparato estatal.

Como resultado, a representação institucional, que já era defasada, piorou com as eleições de 2018. Embora tenha havido incrementos quantitativos - como no número de mulheres eleitas , estes não apontaram, na prática, para um melhor atendimento às demandas gerais da sociedade. Ao contrário, fortaleceram as dominações, agora fantasiadas de "novidade".

Entretanto, não há derrota definitiva nem triunfo definitivo, conforme assinalou o ex-presidente uruguaio Pepe Mujica. Não se deve deixar enganar pelos discursos de "fim da história", mas, sim, evidenciar as contradições e buscar os caminhos possíveis.

\section{Referências bibliográficas}

ABRANCHES, Sérgio. O presidencialismo de coalizão: o dilema institucional brasileiro. Dados, nº 31 (1), 1988, pp. 5-33.

ALMEIDA, Lúcio Flávio Rodrigues de. Por onde recomeçar? As esquerdas e a nova conjuntura pós-eleitoral. Marxismo 21, nov. 2014. Disponível em <https://marxismo21.org/wp-content/uploads/2014/11/Esquerdas-e-a-novaconjunt-p\%C3\%B3s-eleitoral-Lucio-Flavio-de-Almeida-2.pdf>. Acesso em: 11 nov. 2019.

ALMEIDA, Lúcio Flávio Rodrigues de. Neonacional-desenvolvimentismo e relações de classes nos governos Lula. Lutas Sociais, São Paulo, vol. 19, n. 35, jul./dez. 2015, pp. 142-159.

ALMEIDA, Lúcio Flávio Rodrigues de. As relações de classe, a crise o golpe. In: DIAS, Luiz Antonio \& SEGURADO, Rosemary (orgs.). O Golpe de 2016. Razões, Atores e Consequências. São Paulo: Intermeios, 2018, pp. 183-206.

BOLOGNESI, Bruno, COSTA, Luiz Domingos \& CODATO, Adriano. A revolução silenciosa no Partido dos Trabalhadores no Brasil. $10^{\circ}$ encontro da Associação Brasileira de Ciência Política (ABCP). Ciência política e a política: memória e futuro. Belo Horizonte, agosto e setembro de 2016. Disponível em 
<https://cienciapolitica.org.br/system/files/documentos/eventos/2017/04/revoluc ao-silenciosa-partido-dos-trabalhadores-963.pdf>. Acesso em: 13 nov. 2019.

CALLINICOS, Alex. Além do mercado. A vingança da história: o marxismo e as revoluções do Leste Europeu (trad.: Ruy Jungmann). Rio de Janeiro: Jorge Zahar Editora, 1992.

CÁNEPA, Maria Mercedes Loguércio. Partidos e representação política: a articulação dos níveis estadual e nacional no Rio Grande do Sul (1945 - 1965). Porto Alegre: Editora da UFRGS, 2005.

CARAM, Bernardo \& SOUZA, Nivaldo. Congresso eleito é o mais conservador desde 1964, afirma Diap. O Estado de S. Paulo, 06 out. 2014. Disponível em <http://politica.estadao.com.br/noticias/eleicoes,congresso-eleito-e-o-maisconservador-desde-1964-afirma-diap,1572528>. Acesso em: 11 nov. 2019.

CARTA EDUCAÇÃO. "As universidades devem ficar reservadas para uma elite intelectual", diz ministro da educação. 28 jan. 2019. Disponível em <https://www.cartacapital.com.br/educacaoreportagens/as-universidadesdevem-ficar-reservadas-para-uma-elite-intelectual-diz-ministro-daeducacao/>. Acesso em: 05 ago. 2019.

COELHO, Maria Francisca Pinheiro \& SANTANA, Vitor Leal. A geração 68 no Congresso Nacional: Ideologia e comportamento legislativo. Sociedade e Estado, vol. 25, n. 2. Brasília: UnB, mai/ago 2010, pp. 285-307.

CROzIER, Michel J., HUNTINGTON, Samuel P. \& WATANUKI, Joji. The crisis of democracy. Report on the governability of democracies to the Trilateral Commission. Nova York: New York University Press, 1975. Disponível em <http://trilateral.org//download/doc/crisis_of_democracy.pdf>. Acesso em: 05 ago. 2019.

HUNTINGTON, Samuel P. A terceira onda: a democratização no final do século XX. São Paulo: Ed. Ática, 1994.

INSTITUTO BRASILEIRO DE GEOGRAFIA E ESTATÍSTICA [IBGE]. Distribuição percentual da População por Sexo - Brasil - 1980 a 2010. 2010. Disponível em $<$ https://brasilemsintese.ibge.gov.br/populacao/distribuicao-da-populacao-porsexo.html>. Acesso em: 13 ago. 2019.

INTER-Parliamentary Union [IPU]. Women in national parliaments. 2015. Disponível em <http://archive.ipu.org/wmn-e/arc/classif010315.htm>. Acesso em: 11 nov. 2019.

MACIEL, David. Aliança democrática e a transição política no Brasil. In: PINHEIRO, M. (org.) Ditadura: o que resta da transição. São Paulo: Boitempo Editorial, 2014, pp. 269-301.

MACPHERSON, Crawford. B. A democracia liberal: origens e evolução. Rio de Janeiro: Zahar Editores, 1978.

MANIN, Bernard, PRZEWORSKI, Adam \& STOKES, Susan C. Eleições e representação (trad. Felipe Dutch). Lua Nova, n. 67. São Paulo, 2006, pp. 105138. Disponível em <http://www.scielo.br/pdf/In/n67/a05n67.pdf>. Acesso em: 13 nov. 2019.

MARTUSCELLI, Danilo Enrico. A ideologia do "presidencialismo de coalizão". Lutas Sociais, n. 24. São Paulo, 2010, pp. 60-69. 
MARTUSCELLI, Danilo Enrico. Sobre o conceito marxista de crise política. Crítica Marxista $\quad \mathrm{n}^{\circ} \quad 43, \quad 2016$, pp. 9-27. Disponível em <https://www.ifch.unicamp.br/criticamarxista/arquivos_biblioteca/artigo2017_06_ 03_06_32_57.pdf>. Acesso em: 05 ago. 2019.

MARX, Karl. O Capital (Livro 1). São Paulo: Boitempo, 2011.

MILL, John Stuart. Utilitarismo. São Paulo: Ed. Escala, sd.

MORAES, Antônio Carlos de. O projeto neoliberal e o mito do Estado Mínimo. Lutas Sociais, $\quad \mathrm{n}^{\circ} \quad 1,1996 . \quad$ Disponível em <https://revistas.pucsp.br/index.php/ls/issue/view/1214>. Acesso em: 05 ago. 2019.

NAVES, Márcio B. Marxismo e direito: um estudo sobre Pachukanis. São Paulo: Boitempo editorial, 2000.

NERY, Vanderlei Elias. Diretas Já: mobilização de massas com direção burguesa. In: PINHEIRO, M. (org.) Ditadura: o que resta da transição. São Paulo: Boitempo Editorial, 2014, pp. 247-268.

OLIVEIRA, Francisco. O ornitorrinco. In: Crítica da razão dualista / O ornitorrinco. São Paulo: Boitempo, 2003 apud ALMEIDA, Lúcio Flávio Rodrigues de. As relações de classe, a crise o golpe. In: DIAS, Luiz Antonio \& SEGURADO, Rosemary (orgs.). O Golpe de 2016. Razões, Atores e Consequências. São Paulo: Intermeios, 2018, pp. 183-206.

PITKIN, Hanna Fenichel. The concept of representation. Berkeley e Los Angeles, California: University of California Press, ed. 1972.

POULANTZAS, Nicos. As transformações atuais do Estado, a crise política e a crise do Estado. In: POULANTZAS, Nicos. (Org.). O Estado em crise. Rio de Janeiro: Graal, 1977, apud MARTUSCELLI, Danilo, op. cit., 2016, pp. 9-27.

POULANTZAS, Nicos. Introdução: as classes sociais e sua reprodução ampliada. In: As classes sociais no capitalismo de hoje. Rio de Janeiro: Zahar Editores, 1975.

POULANTZAS, Nicos. O problema do Estado capitalista. In: BLACKBURN, R. (org.). A ideologia na ciência social: ensaios críticos sobre a teoria social. Rio de Janeiro: Paz e Terra, 1982.

REDE BRASIL ATUAL. Maiores bancos do país devem mais de R\$ 124 bilhões para a União. $06 \quad$ jul. $2017 . \quad$ Disponível em <https://www.redebrasilatual.com.br/economia/2017/07/maiores-bancos-dopais-acumulam-mais-de-r-124-bilhoes-em-dividas-com-a-uniao-1/>. Acesso em: 15 ago. 2019.

SAES, Décio. Democracia. São Paulo: Ed. Ática, 1987.

SAES, Décio. República do capital. Capitalismo e processo político no Brasil. São Paulo: Boitempo. 2001.

SARDINHA, Edson. Só 3\% dos eleitos em 2014 se declaram negros. Congresso em foco, 18 dez. 2014.2 Disponível em <http://congressoemfoco.vol.com.br/noticias/so-3-dos-eleitos-em-2014-sedeclaram-negros/>. Acesso em: 11 nov. 2018.

SCHUMPETER, Joseph Alois. Capitalismo, socialismo e democracia. Rio de Janeiro, Ed. Fundo de Cultura, 1961. 
SILVA, Sérgio. Expansão cafeeira e origens da indústria no Brasil. São Paulo: Ed. Alfa-Omega, 1986.

VEJA. Universidades com 'balbúrdia' terão verbas reduzidas, diz Weintraub. 30 abr. 2019. Disponível em <https://veja.abril.com.br/brasil/universidades-combalburdia-terao-verbas-reduzidas-diz-weintraub/>. Acesso em: 05 ago. 2019. 